\title{
Tres personajes en busca del lugar perdido
}

\section{Three Characters in Search of a Lost Place}

\section{Kimsa runakuna huk chinkasqa kitita maskaq}

\section{Vanessa Vera Chaparro ${ }^{1}$}

Universidad Científica del Sur, Lima, Perú

vanessa_textos@hotmail.com

\section{RESUMEN}

Los geniecillos dominicales (1964), Conversación en La Catedral (1969) y Los verdes años del billar (1986) son novelas protagonizadas por jóvenes personajes, cuyas acciones se llevan a cabo en una sociedad peruana sometida por la dictadura militar. Ludo Totem, Santiago Zavala y Ricardo Yáñez experimentan una crisis individual como consecuencia de la ruptura que establecen con su lugar de origen (familia, clase social, círculos sociales). Nos interesa aquí determinar y analizar los factores de dicho distanciamiento y el efecto que ejerce sobre el proceso formativo de estos. Para ello, el esquema tripartito que propone Edward Said (2004): filiación, filiación problemática y afiliación, funcionará como el marco teórico de nuestro estudio. Con su ayuda, demostraremos que estos personajes son agentes trastocados por una violencia pública que se internaliza en los espacios privados que habitan para desfigurarlos e incluso desaparecerlos.

\section{PALABRAS CLAVE}

Ludo, Santiago, Ricardo, filiación, afiliación

\section{ABSTRACT}

Los geniecillos dominicales (1964), Conversación en La Catedral (1969) y Los verdes años del billar (1986) are

1 Egresada de la maestría en Literatura Peruana y Latinoamericana de la Universidad Nacional Mayor de San Marcos. Licenciada en Literatura por la Universidad Nacional Federico Villarreal. Ha publicado y expuesto trabajos acerca de narrativa peruana de la segunda mitad del siglo XX. Se desempeña como docente en la Facultad de Humanidades de la Universidad Federico Villarreal y en Cursos Básicos Humanidades de la Universidad Científica del Sur. 
novels represented by young characters, whose actions are executed in a Peruvian society subjugated by a military dictatorship. Ludo Totem, Santiago Zavala y Ricardo Yáñez experienced an individual crisis because they broke their relationship with their place of birth, social class and economic status. We will investigate and analyze such rupture. We are going to use the theory proposed by Edward Said (2004): filiation, affiliation and membership problems. This theory will work as a theoretical framework in this class. At the end, we are going to demonstrate how an internal violence coexist in a private space in those character's life.

\section{KEYWORDS}

Ludo, Santiago, Ricardo, filiation, affiliation

\section{PISILLAPI QILLQASQA}

Dumigupi ruwaq supaychakuna (1964), La Catedral nisqapi parlanakuy (1969), Chiqlla billarpa watankunapa (1986), kaykunaqa nuwila willakuykunan kan. Malta runakunamantan willakamun, maqtakunamantapuni. Tukuy imata ruwasqankunaqa kanmi, pasarunmi, wallapa suqaIliqninpa pachapi. Ludo Totemqa, Santiago Zavala hina, Ricardo Yáñez hinapas yañaykunko ancha sasachaykunata chay chupulunkuta pakiramusqanmanta. ¿Imanasqataq paykunaqa karunchakuraku?, ¿imataq lluqsiramun chayna ruwasqankumantaqa? Chaykunatan yachayta atirusun kay qillqasqawanqa. Kaykunata yachanapaqa Edward Saidpa nisqanta yuyarisun: filiación, filiación problemática y afiliación nisqanta. Kay nisqanmi kanqa allin chaniyuq yachay.

\section{TIQSI RIMANAKUNA}

Ludo, Santiago, Ricardo, filiación nisqan, afiliación nisqan, simi kapchiy

Durante la segunda mitad del siglo XX, el Perú ha sido el escenario para la actuación de varios personajes que lucían vestuario castrense; pero entre ellos tres son de especial importancia: Manuel A. Odría, Juan Velasco Alvarado y Francisco Morales Bermúdez. Cada uno de ellos, con sus propias políticas de represión social y de populismo, intervino en el forjamiento de diversos tipos de agentes sociales que modelaban su conducta y postura de acuerdo con su perspectiva de la situación social. Uno de ellos fue el sujeto fragmentado por la imposibilidad de definir su posición, el temor de abandonarla o la inminente desarticulación de su 
lugar seguro: la clase social de la que provenía. La novelística peruana, por supuesto, no fue ajena a este horizonte histórico, y desde sus estrategias ficcionales abordó como marco referencial los hechos que la realidad le ofrecía. Precisamente, las novelas que analizamos aquí — Los geniecillos dominicales (1964), Conversación en La Catedral (1969) y Los verdes años del billar (1986) - proponen tres prototipos de jóvenes, cuyas vidas se desarrollan en el marco de un gobierno militar. Estas novelas, con mayor o menor precisión, logran expresar de modo representativo un clima social de represión y autoritarismo.

El origen social de los personajes que estudiamos, Ludo, Santiago y Ricardo, se verá desestabilizado por dos factores: uno de carácter privado, el periodo de madurez que afecta sus relaciones sociales y familiares, debido a que todos intentan definir su lugar en el mundo, y otro de naturaleza pública, la convulsionada vida urbana marcada por la violencia, la cual fácilmente se puede considerar una extensión del autoritarismo que los gobiernos militares proyectan. Como se sabe, pues, tanto la novela de Ribeyro como la de Vargas Llosa aluden al gobierno de Odría, mientras que en el caso de Los verdes años del billar, la referencia no se define claramente entre Velasco o Morales Bermúdez; pero, por las marcas textuales identificadas, definitivamente es un militar quien gobierna.

El conflicto interno de los protagonistas se manifestará mediante un alejamiento de su clase social de origen. Voluntaria o involuntariamente, Ludo, Santiago y Ricardo experimentarán un lento desclasamiento que les exigirá tomar conciencia de la clase a la que pertenecen y que los pondrá en contacto con otra. Estos individuos lograrán reconocer su clase una vez que se interrelacionen con sujetos que representan otra; ya que la unión de los individuos como integrantes de una misma clase social implica la existencia de intereses comunes que se evidencian en la interacción de grupos sociales distintos. Esto, en el caso de los tres personajes, propicia que su original posición social experimente una trayectoria de cambio que afectará su proceso de desarrollo.

Si analizamos las condiciones de vida correspondientes a Santiago, Ludo y Ricardo, la configuración en términos de clase está claramente definida; de tal modo que las prácticas que llevan a cabo en el desarrollo de sus historias nos pueden señalar la clase social a la que pertenecen por nacimiento. Una clase que han heredado, pero contra la que, en el momento más crucial de sus existencias, inician una serie de conflictos, los cuales nos permiten constatar en las novelas estudiadas la posibilidad que los protagonistas tienen de desligarse de su clase e ir contra ese supuesto lugar que esta les ha asignado. 
A pesar de que ninguna de las novelas analizadas plantea una subversión del estado económico-social que los personajes presencian, logran, a través de los protagonistas, establecer una crítica a las condiciones sociales que han heredado. Esto, a su vez, les permite escapar, no sin dificultades, de ese influjo que la clase de origen ejerce sobre ellos.

De acuerdo con nuestro objetivo de analizar el desplazamiento de los personajes, requerimos definir primero la clase a la que cada uno de ellos pertenece por filiación (Said, 2004). Por esta categoría entendemos, desde la propuesta de Said, un lazo meramente natural, como el que existe entre los integrantes de una familia, donde la autoridad tiene fundamento biológico. Según el esquema tripartito que nos sirve de modelo, debemos empezar estableciendo el lugar de origen de Ludo, Santiago y Ricardo.

Iniciemos con el caso de Ludo. Su rama familiar está siempre en contraste con la opulencia de los otros familiares que mantienen su estatus social y ostentan una gran fortuna, de tal modo que pueden organizar grandes fiestas y vivir en los espacios más privilegiados de Lima; mientras que la familia de Ludo debe buscar un lugar que se ajuste a su nueva condición económica, pues, para agravar su situación, su familia ha ido perdiendo sus propiedades paulatinamente:

Pero poco después estaban en la casa de Pirulo, frente a la avenida Sáenz Peña. Ludo se sentía atraído por esa casa: hojeando un día un viejo álbum de fotografías familiares había descubierto que esa casa perteneció a su abuelo, hacía unos cincuenta años [...]. Muchas otras casas había ocupado su familia, de las cuales Ludo solo conocía la fachada, la de Washington, la de Belén, y sobre todo la de Espíritu Santo, gigantesca, convertida ahora en una escuela secundaria (Ribeyro, 1973, p. 51) (el resaltado es nuestro).

Esta referencia a un pasado ostentoso devela la crisis en la que la familia de Ludo se ve envuelta. La posesión de una mansión no es para Ludo ni siquiera un recuerdo, es la fascinación por los placeres de una época que no alcanzó a disfrutar; pero, sobre todo, el tormento de ser testigo de la fragmentación de la historia de su familia, a la que desea aferrarse. De ahí que no sea capaz de ver en ese lugar lo que es ahora: la casa de su amigo Pirulo. Su mirada nostálgica solo visualiza el espacio en que su abuelo jurista «redactó algún brillante alegato» (p. 51).

Otro aspecto que nos puede ayudar a continuar con el establecimiento de los contornos que dibujen la clase social de Ludo son los símbolos que su familia fue dejando de modo dispersado por una Lima que iba cambiando rápidamente no solo su estructura física, sino social, debido a un proceso de modernización que implicaba dejar atrás ciertas tradiciones que no fueron capaces de adaptarse al nuevo sistema. Por ejemplo, 
estando en la casa de su tía Rosalva, se encuentra con que algunos de sus muros lucían varias fotografías que retrataban a los antepasados de su familia:

Ludo empezó a encontrar divertidos los retratos y cuando veía un rostro demasiado agrio se sentía tentado de pedirle excusas o hacerle una reverencia. Pero tuvo que interrumpir su juego al distinguir, encuadrada en un lujoso marco dorado, su propia fotografía. [.... Era una foto de juventud de su abuelo fechada en 1876 (p. 77).

La imagen enmarcada de su abuelo nos remite a un pasado aristocrático. Lo que es más: la forma en que posa: «Sostenía en una mano un guante y con otra hojeaba un libro colocado en un atril» (p. 77) da cuenta de un pasado mejor, donde su abuelo representaba una figura ilustrada; asimismo, la reacción que Ludo manifiesta ante esta imagen condensa en unas cuantas líneas la orientación de su historia: «La contempló con avidez, sintiéndose sin saber por qué profundamente desgraciado» (p. 77). Este encuentro, dado en un solo párrafo, en el que Ludo se ve frente a su abuelo, sirve para ilustrar la decadencia social y también existencial de Ludo, siempre en función de lo que fue su pasado familiar.

Según la marca temporal que Los geniecillos dominicales consigna: 1876, y tomando en cuenta la información que proporciona Ludo en cuanto a su abuelo, representante de su linaje — juristas que vivían en mansiones-, podemos sostener que Ludo desciende de una clase ilustrada: la aristocracia de la inteligencia. Sin embargo, en la nueva realidad limeña, los elementos que son propios de dicha clase -recordemos que Ludo está a punto de recibirse como abogado- se convierten en obsoletos, debido a la acelerada decadencia que experimenta la rama familiar de Ludo en un contexto de cambio social, en el que una nueva clase que aparecería a inicios del novecientos empezaría a consolidarse sobre la base de la industria y el comercio: la burguesía (Cotler, 1978).

Señala Washington Delgado (1973) que Ludo es un «personaje paradigmático de un mundo pequeño burgués» (p. 14). La pequeña burguesía como estrato de transición es efectivamente la clase a la que Ludo pertenece en el tiempo cero del relato, una clase media en tanto ya no posee los privilegios económicos que sus ascendientes fueron perdiendo. Lo que observamos es que la familia de Ludo no alcanzó a mantener su situación privilegiada, y, como lectores, asistimos a su declive. Ludo recibirá las consecuencias del decaimiento de su linaje y las transformará en su propia crisis, en un problema individualizado:

Ludo tenía la viva conciencia de que el espacio de que antes disponían los suyos se había ido comprimiendo, cada generación perdió 
una alcoba, un patio. Ahora solo les quedaba el ranchito de Miraflores. Quizá algún día le quedaría a él nada más que un aposento, cuatro paredes ciegas, una llave. (Ribeyro, 1973, pp. 51-52).

Un pensamiento que se convertirá en una premonición, cuando hacia el final de la novela, en un cuarto, con la idea del suicidio, termine rasurándose el bigote en seco, como expresión máxima y única de heroicidad. En la cita se ve también lo que acabamos de señalar: Ludo se impregna la gradual decadencia de cada generación, como si únicamente él asumiera toda una historia plagada de errores y fracasos.

Elmore (1993) nos ha proporcionado ya algunas luces sobre este punto; sostiene que Ludo pasa por un «desclasamiento», el cual entendemos como la experimentación de una movilidad social hacia la decadencia: «Trayecto del personaje de la respetabilidad burguesa ${ }^{2}$ a los bajos fondos limeños» (Elmore, 1993, p. 153), mediado por la «ruptura de los lazos que atan a Ludo Totem con su grupo de origen» (p. 153). Posteriormente, retomaremos el análisis de este personaje, a fin de constatar que si Ludo no halla «en su familia la posibilidad de una filiación aceptable» (Elmore, 1993, p. 154), es también porque esa misma familia, fundándose en criterios de clase, rechaza los vínculos con él.

Nos corresponde ahora establecer la filiación de Santiago: la familia Zavala es contundentemente burguesa. Marx y Engels sostienen acerca de esta clase:

La burguesía suprime cada vez más el fraccionamiento de los medios de producción, de la propiedad y de la población. Ha aglomerado la población, centralizado los medios de producción y concentrado la propiedad en manos de unos pocos (Marx y Engels, 1999, pp. 27-28).

Efectivamente, de acuerdo con las relaciones de producción, es la configuración de la burguesía (clase alta) ${ }^{3}$ lo que se pretende representar en Conversación en La Catedral: la familia de Santiago posee una fábrica (laboratorio farmacéutico) en la que trabajan obreros asalariados; en otras palabras, los Zavala controlan parte de los medios de producción y controlan mano de obra a su disposición:

2 La burguesía es una clase que no tiene presencia en la novela de Ribeyro, debido a que los dos grupos que se oponen, el pasado representado por el abuelo y el presente, cuyo exponente es Ludo, no manifiestan un rasgo burgués determinante: ninguno de los dos grupos maneja los medios de producción. Por otro lado, es importante anotar que si bien el abuelo de Ludo es un jurista y, por tanto, un burócrata, posee numerosas propiedades. Por otro lado, en el relato se evidencia una clara intención de presentarlo como un hombre erudito, al igual que el otro antepasado de Ludo: el rector de la Universidad San Marcos.

3 En Conversación en La Catedral, se percibe un periodo de consolidación de la burguesía. A lo ya mencionado, se suma que el personaje Trinidad López trabaja en una fábrica textil. Incluso, se hace referencia al Hospital Obrero. 
—Ya están saliendo de las fábricas — dijo Amalia—. Lástima que el laboratorio de su papá no esté por aquí, niño. Hasta la avenida Argentina voy a tener que tomar el tranvía y después ómnibus.

— ¿Vas a trabajar en el laboratorio? — dijo Santiago.

— ¿Su papá no le contó? — dijo Amalia-. Sí, pues, desde el lunes.

Ella estaba saliendo de la casa con su maleta y encontró a don Fermín, ¿quieres que te coloque en el laboratorio?, y ella claro que sí, don Fermín, donde sea, y entonces él Ilamó al niño Chispas y le dijo telefonea a Carrillo y que le dé trabajo (Vargas Llosa, 2005, p. 54) (el resaltado es nuestro).

Posteriormente, en una escena en la que Amalia se encuentra trabajando en la fábrica de don Fermín nos es posible apreciar también la forma en que el trabajo está dividido: «A las que colocaban las tapas les decían taperas, etiqueteras a las que pegaban las etiquetas, y al final de la mesa cuatro mujeres recogían los frascos» (p. 102). Todo este trabajo asalariado es el que nutre la riqueza de la familia Zavala, de modo que cuando Cayo Bermúdez logra cerrar su laboratorio, la situación económica de don Fermín entra en crisis.

A esto se suma que don Fermín sostiene relaciones con grupos acentuados en el poder gobernante. Como sabemos, la mayor parte de los hechos transcurre durante el gobierno militar de Odría, a quien el padre de Santiago apoya: «Quiero contarles algo de una vez — Santiago apretó los puños debajo de la mesa y tragó saliva-. Mi padre está con el gobierno» (p. 97).

En función de esta pertenencia social, Santiago y sus hermanos, la Teté y el Chispas, asistieron al «mejor colegio de Lima», sus padres anhelan que Santiago estudie Derecho en la Universidad Católica y la señora Zoila expone su rechazo a la Universidad San Marcos. Pero estas costumbres y formatos conductuales de su familia son rechazadas por Santiago, quien toma decisiones que lo distancian de su lugar de origen, como ingresar a San Marcos y no a la Católica o escaparse de su casa. Incluso, sus hermanos se refieren a él con denominaciones como «supersabio»; con esto dan a entender que lo juzgan de extraño por su modus vivendi.

Por su parte, Ricardo se autodefine como un pequeño burgués; la lucha que él establece es contra el sistema de valores de su clase. Los titubeos de su contingente desplazamiento corresponden a su posición en la jerarquía clasista: ser un pequeño burgués equivale a ser un sujeto de clase media, y la estratificación de esta clase se define en comparación a las clases superiores e inferiores.

La persistente indefinición de Ricardo consiste en si su pensamiento está en consonancia con la clase alta o la clase popular. Estas relaciones 
de clase son las que enmarcan el conocimiento que Ricardo llegará a interiorizar como parte del desarrollo de su conciencia.

La representación de su familia pequeñoburguesa está más compuesta por señales de tipo conductual, antes que materiales; dentro de estas últimas encontramos la casa en Miraflores, las vacaciones en los balnearios limeños, una sirvienta en casa, un colegio prestigioso y caro, la universidad extranjera de su hermano y otras referencias poco definidas. Pero en cuanto a las señales del primer tipo, son abundantes los rasgos psicológicos de esta clase, algunas muestras son la exigencia de respeto hacia las instituciones como la justicia:

Solo Dios en su infinita bondad [afirma su tía Queta] es capaz de entender las debilidades humanas y perdonar; pero nosotros los hombres tenemos que defendernos de los malos, de los que nos pueden hacer daño, de los que toman la propiedad ajena. Esos hombres son los policías. ¿Qué haríamos sin los policías que nos cuidan? Cualquiera podría robarnos, hasta matarnos, porque hay gente muy mala, gente que asalta, que roba (Reyes Tarazona, 1986, p. 194).

La educación y la Iglesia son considerados los pilares de la formación correcta en aras de ascender socialmente; muestra de esto es el interés del padre de Ricardo en que mantenga una actitud intachable en la escuela y sepa corresponder el esfuerzo que hace día a día para costear sus estudios: "¿¿Tú sabes cuánto pago mensualmente? Y la matrícula ¿Sabes cuánto costó?". Sí lo sabía, por supuesto: tantas veces lo había dicho en el transcurso del año por diferentes motivos» (p. 28).

En la segunda fase del esquema de Said se ubica la imposibilidad de mantener estables y permanentes los lazos biológicos (la filiación), lo cual genera la urgencia de una nueva forma de comunidad: afiliación. Este tercer estadio es creado en la práctica de la socialización que involucra personas con las que no se posee un vínculo biológico.

En el texto que citamos a continuación, Said señala la relación que existe entre ambos estadios, además de algunos ejemplos de afiliación:

Lo que estoy describiendo es la transición de una idea o posibilidad de filiación fallida hacia una especie de orden compensatorio que, ya sea un partido político, una institución, una cultura, un conjunto de creencias o incluso una visión del mundo, proporciona a hombres y mujeres una nueva forma de relación, a la cual he estado denominando afiliación pero que también constituye un nuevo sistema. (Said, 2004, p. 34).

La afiliación consiste en acciones con mayor grado de complejidad; la conciencia de gremio, por ejemplo, es el acto por el que un individuo se 
incorpora a una asociación y, consecuentemente, permite que el grupo proyecte sobre él sus principios al mismo tiempo que encuentra similitud entre estos y sus objetivos personales, lo cual realiza de modo voluntario y no movido por fundamentos biológicos.

Como ya la señalamos, Ludo y su familia provienen de una aristocracia de la inteligencia; de ahí la presencia de un acomodado pasado que se fue diluyendo, expresado en los recuerdos de la infancia de Ludo: el Club Regatas, las antiguas propiedades de la familia, un antepasado que fue rector de la Universidad San Marcos —José Armando Totem, su bisabuelo-, el prestigioso colegio, y algunos hechos: el enamoramiento de la Walkiria o la conducta religiosa, que simbolizan una feliz y despreocupada etapa. Así se va configurando un referente. Este pasado no contribuye a sostener el ser de Ludo, por el contrario, dramatiza su situación actual. Los jóvenes personajes suelen acudir a su pasado para hallar las respuestas que buscan para alcanzar la madurez; pero Ludo no solo no obtiene esto de las escenas de su infancia o adolescencia, sino que estas se convierten en los principales factores que destacan lo terrible de su presente.

De manera simultánea a la crisis generacional que experimenta, acompañando sus acciones de la misma «sensación de derrota», Ludo frecuenta prostíbulos de La Victoria, el Callao y Surquillo. A través de los actos delictivos que comete y de la relación no correspondida que inicia con la prostituta Estrella, quien terminará extorsionándolo, Ludo va incorporándose a la lógica de una Lima periférica: «Ludo tuvo por primera vez la impresión de haber descendido varios grados en la escala humana, hasta esa zona indecisa que linda con la animalidad» (Ribeyro, 1973, p. 55).

Para reforzar lo que estamos sosteniendo acerca de este tipo de movimiento experimentado por Ludo, son numerosos los pasajes que muestran su paulatina separación de la clase social heredada y ahora arrebatada; pero mucho más emblemáticas son las escenas de la boda de su tía Rosalva:

Hemos contratado [le dice a Ludo su tío Carmelo] también un equipo de mozos, pero estos zamarros todavía no llegan. Seguramente están sindicalizados. Cuando te vi aparecer creí que eras uno de ellos que venía a darme una mala noticia. Ludo no pudo evitar el echar una mirada a su propio terno oscuro, lustroso y un poco marchito por tantos años de servicio (p. 78).

No obstante, esta aparente incorporación no funciona como afiliación efectiva. El desplazamiento de Ludo hacia otra clase queda solo en un intento, una serie de actos fallidos que Ludo ejecuta para conseguir adaptarse al mundo propio de otra clase social que llene el vacío dejado 
por la desaparición de los lazos que lo unían a su clase de origen. Puede apreciarse que es apartado de su clase, pero no alcanza una sustitución: es rechazado por este mundo de las clases bajas, es golpeado por un proxeneta, involucrado sin planearlo en un asalto, rechazado por Estrella e, incluso, desde lo alto de los pisos superiores, él mismo se percata de que no encaja en la universidad San Marcos; la distancia espacial vertical que separa a ludo de los estudiantes sanmarquinos así se encarga de corroborarlo.

Este intento de desplazamiento incluye, según observamos, el obligado desligue 4 de su clase de origen (a la que estuvo afiliado) —aunque no exista un punto de llegada - lo que equivale a una movilidad de tipo involuntario ${ }^{5}$, que lo termina conduciendo a un vacío.

Vargas Llosa (1966) Ilama la atención sobre Ludo como escritor: esta vocación es, afirma, la verdadera actividad de ruptura con la sociedad (más allá de su «condición familiar» como «clave de su fracaso») que experimenta Ludo: Ribeyro demuestra, en esta línea: «La terrible soledad del creador, la incompatibilidad fundamental entre la sociedad y el artista» (p. 11). Nos parece totalmente válida esta propuesta de Vargas Llosa; pero ella no suprime la lejanía de Ludo respeto a la clase burguesa, pues, al elegir convertirse en escritor, entra en conflicto con el pensamiento pragmático y materialista de esta clase que prefiere abogados o ingenieros. Agreguemos que cuando hablamos del escritor-Ludo se introduce la palabra elección: él elige escribir cuentos, esta actividad excluyente y poco aceptada por la sociedad motiva el surgimiento de una elección sin condicionamientos. Lo que queremos decir es que en la ruptura filiativa de Ludo se encuentran la obligación y la libertad: por un lado, es expulsado de la burguesía; por el otro, él origina su exclusión a través de la literatura.

Veamos a continuación si llega a darse el estadio de la afiliación en Conversación en La Catedral: en San Marcos, Santiago conoce a Aída y Jacobo, participantes de un movimiento social al que Santiago se integra; así irá intensificando la distancia que interpondrá entre su familia y sus intereses particulares; no obstante, al mismo tiempo aparecen las dificultades de todo desplazamiento de clase:

4 Esto diferencia a Ludo de Santiago y Ricardo, porque los dos últimos eligen separarse de su familia como consecuencia de diversas incompatibilidades.

5 A pesar de poseer los «credenciales» que por generaciones le fueron otorgados: el apellido Totem, el mismo apellido que encontró en un juego de ostentosos cuadros de sus antepasados o en las paredes sanmarquinas: "José Armando Totem fue rector de esta universidad de 1856 a 1864» (Ribeyro, p. 112), además de los rasgos físicos, Ludo no es reconocido por el ala rica de la familia como digno integrante: sufre así la negación de los otros. 
¿Te daba vergüenza, Zavalita?, piensa: ¿Que Jacobo, Héctor, Solórzano no vieran dónde y con quién vivías, que no conocieran a la vieja y no oyeran al viejo, que Aída no escuchara las lindas idioteces de la Teté? Piensa: ¿o que la vieja y el viejo no supieran con quién te juntabas, que el Chispas y la Teté no vieran la cara de huaco del cholo Martínez? Ese primer día comenzaste a matar a los viejos, a Popeye, a Miraflores, piensa. Estabas rompiendo, Zavalita, entrando a otro mundo: ¿fue ahí, se cerraron ahí? Piensa: ¿rompiendo con qué, entrando a cuál mundo? (Vargas Llosa, 2005, p. 93) (el resaltado es nuestro).

Santiago, según Elmore (1993), es un «personaje que escoge convertirse en un perdedor». Su «automarginación» (p. 195) lo convierte en un «testigo privilegiado de la fisura radical que constituye al mundo representado: si la felicidad le es inalcanzable, le resta a modo de compensación una amarga lucidez» (p. 195). No obstante, en lo que Elmore ve una compensación, nosotros percibimos, además de la expresión de la conciencia crítica de Santiago, aquello que le impedirá encontrar un soporte que reemplace la pérdida del foco familiar. La elección de Santiago es el inevitable camino que lo llevaría a verse condenado a un no lugar, a la negación de la pertenencia: un proyecto inconcluso.

Su renuncia a los beneficios que le corresponde como burgués lo inducen a buscar un lugar donde su pensamiento encuentre eco; pero, como todo proceso personal, encontrará problemas de coherencia y pertenencia. Las características físicas de sus amigos sanmarquinos difieren inequívocamente de los de sus hermanos; su grupo de estudios repudia el gobierno odriista, mientras que su padre trabaja para este; agreguemos a ello que no le resulta fácil interiorizar las máximas al partido que contradictoriamente tanto desea pertenecer. En conclusión, rasgos diferenciadores que hacen visible la jerarquía social. Por estas y otras carencias de determinación, rechaza la posibilidad de convertirse en militante político del comunismo. En la negación de uno (burguesía) y otro grupo (la organización popular) a donde adherirse, Santiago aborta las posibilidades de definir la tendencia de su ideología, para quedar en una especie de limbo: «Consuélate, la profecía no se cumplió — dijo Carlitos- Ni abogado ni socio del Club Nacional, ni proletario ni burgués, Zavalita. Solo una pobre mierdecita entre los dos» (Vargas Llosa, 2005, p. 180).

Santiago se presentaba como «puro», pero al no sentirse capaz de ingresar al partido - indicador de que no está exento de las nefastas consecuencias del poder, porque aún no ha llegado a separarse por completo de su clase-, rechaza esta condición. En el trabajo que desempeña como periodista de La Crónica está en contacto con el sistema de antivalores de 
su clase - al destaparse los misterios de la muerte de la Musa-. Más aún, al no asumir su agencialidad social y optar por el silencio y, por tanto, la inacción, Santiago participa de la corrupción como un testigo mudo que no denuncia. Es decir, su propia condición burguesa siempre lo perseguirá y saboteará sus proyectos.

Él se instala de manera física en una clase social diferente a la recibida por herencia, casado con una enfermera, Ana, habitando una quinta, habiéndose negado la posibilidad de disfrutar de una herencia. En suma, un desplazamiento figurativo, una falsa afiliación, que no llega a concretar una compatibilidad con la clase de llegada. Santiago no llega a interiorizar el pensamiento propio de la clase obrera; pero tampoco mantiene incólume su ideología burguesa. Lo que sí vemos en él es que asume un problema propio de la clase media: la indefinición, y ante ella todas sus posibilidades de convertirse en agente de una nueva clase se subyugan.

En cuanto a Los verdes años del billar: como consecuencia de la influencia que Ricardo recibe del personaje Maese Diego, participante de la guerra civil española, ciertas ideas definirán en Ricardo su apego a la clase popular y no a la burguesía. Maese Diego es quien fomenta en Ricardo la toma de una postura, la decisión de optar por sus propias creencias, independientemente de lo que su clase le exija pensar: «" ¿Sí? ¿Y tú buscarás tu propio camino algún día?", dijo [Maese Diego]» (Reyes Tarazona, 1986, p. 198).

Consecuente con esta personalidad que se iba forjando, Ricardo inicia su contacto con la Lima popular. Paulatinamente, se aleja de su colegio parroquial de «niños bien» para frecuentar el taco del Maleño en los días en que evadía sus clases, cansado de los esquemas conductuales que los profesores y sacerdotes le exigen cumplir.

Más tarde, brota la necesidad de alcanzar madurez ideológica y asumir su agencialidad en la sociedad que frecuenta como nuevo espacio. Es así que girará su interés hacia la organización social, adoptando una actuación política; lo que desde ya implica una coincidencia de intereses con el grupo de estudios que integra. Sin embargo, aparecen en su trayecto de conversión los primeros obstáculos, propios de la complejidad de toda movilidad social, de toda afiliación.

Entre las situaciones que dificultan el movimiento de Ricardo hacia una clase distinta a la suya, podemos encontrar desde la apariencia que mantiene, y de la que siempre es consciente: «Seguro que nunca se imaginó que alguien capaz de levantarse un libro pudiera tener el aspecto de un muchacho de buena familia» (p. 64), hasta los recuerdos de una vida cómoda, opuesta a las carencias de la nueva clase. 
Al mismo tiempo, Ricardo trata de demostrar que no deja de ser consciente de los momentos en que su proyecto puede fracasar; tampoco ignora las experiencias en que debe identificar los comportamientos de clase que quiere excluir de sus acciones.

La novela demuestra también que el desplazamiento de clase no es un acto inmediato, motivado por la decisión voluntaria; es todo un proceso lleno de encuentros, dudas, rechazos, etc., y qué mejor que un narrador autodiegético (en primera persona) que dé a conocer o, en todo caso, haga evidente al lector las vicisitudes de su conciencia en el cambio que se propone llevar a cabo.

Ricardo refuerza su apego hacia las clases bajas con hechos emblemáticos como la huida de su casa. En las penurias que debe pasar subyace parte importante del desplazamiento: la convivencia con la clase baja acentúa el distanciamiento de la clase dominante.

Él es consciente de las normas que debe ejecutar para responder coherentemente a las situaciones que vivirá como parte de esta colectividad $y$, de este modo, encajar en ella o, por lo menos, disminuir los problemas de pertenencia. Por ejemplo, vemos esta preocupación cuando da cuenta de las razones que lo empujaron a abandonar su hogar: «Para prepararme ideológica y políticamente mejor, para documentarme y sentirme en menor desventaja cuando se producía un debate y se esperaba la participación y el aporte de todos los presentes» (p. 30). Él manifiesta el deseo de estar capacitado para integrar sin mayores problemas el grupo del Profe. Evidentemente, intuye una desventaja en relación con los otros integrantes; en su interés por desaparecerla, nosotros identificamos una necesidad de legitimar los lazos entre él y el grupo, de justificar sus pertenencia a él.

Desde el momento en que Ricardo acepta ingresar al grupo de estudios del Profe, de tendencia marxista, acepta también sus pautas, el programa de lecturas, participar en las protestas como las huelgas, entre otros modos de llevar a la acción el pensamiento revolucionario. Sin embargo, se presenta un profundo quiebre entre la figura revolucionaria que el Profe le exige encarnar a Ricardo y la particular personalidad de este.

Por otro lado, el billar ejerce una atracción profunda sobre Ricardo, le atraen sus tácticas, las bromas de la collera, el azar del juego; el Gato es la personificación de este mundo donde afloran los deseos del ser humano. Esto último nos lleva a pensar que no es coincidencia que Ricardo vea en la amante del dueño del taco una provocación sexual.

Este juego es la otra cara de la potencial realidad de Ricardo, accede a él antes que a la militancia política; su interés en este juego es el que termina siendo la razón de una fuerte discusión que sostiene con el Profe; 
la cual desemboca en su alejamiento, no es claro en realidad ni definitivo, de la célula de estudios.

Ricardo oscilará entre la militancia política o la evasión que le ofrece el billar, sin saber cómo ordenarlos y distribuirlos en su vida. Esta indecisión es para nosotros un valioso indicador del nuevo conflicto que asume Ricardo, ya no el de ser pequeño burgués o aliarse con las clase popular; sino el der ser militante o billarista.

Cuando Ricardo se anima a compartir con los asiduos asistentes del taco, su postura ideológica se encuentra con una total indiferencia; esto le provoca un desconcierto que se reafirmará cuando, camino a presenciar el duelo, escucha las frases despectivas de sus acompañantes respecto a los huelguistas. Ricardo comprende en ese instante que los problemas originados en el régimen que regula la sociedad son en parte producidos por cada uno de ellos, por su negación a solidarizarse con los movimientos desatados en contra del Gobierno y las clases económicas dominantes.

De este modo, la afiliación se presenta en la experiencia de Ricardo cuando asume que su función social no se ubica en la clase pequeñoburguesa. La afiliación de Ricardo implicó un paulatino cambio de posición ideológica; el hecho más contundente sucede cuando deja de pensar como un pequeño burgués para pasar entender y defender la protesta popular, y asumir sus preocupaciones.

Con la finalidad de completar la perspectiva de la naturaleza oscilante de la pequeña burguesía, debemos señalar lo que sucede con su familia: a diferencia de Ricardo, esta tiene solo los propósitos de reforzar los intereses del grupo dominante a través de su sistema de costumbres, negándose así la posibilidad de tener una ideología distinta a la burguesa. Por ello, a Ricardo no le es posible encontrar la identidad original que necesita; al ver en su familia remedos, busca otras opciones: la búsqueda de un sistema original, al que encuentra en el mundo de las clases populares.

Todas estas experiencias que rodean la afiliación de Ricardo ocasionarán que el problema adquiera otro cariz: su clase de origen ya no es más un persistente recuerdo que lo invita a regresar a sus confines, representa ahora con mayor fuerza todo lo que Ricardo no desea ser, en oposición a ella se presenta ya no la posibilidad sino el hecho de haber adquirido su propia perspectiva de la realidad, de hacer válida una interpretación propia de su vida, comulgando - la estricta armonía no es definitivamente un requisito para que un individuo se integre a un grupo social, pues siempre mantendrá una línea de pensamiento que podrá o no podrá ser compatible con la mayoría - con un nuevo colectivo que lo acepta dentro de sus filas. Esto demuestra que Ricardo lleva a cabo de manera exitosa 
su afiliación; para él ya no es más una opción su antigua filiación, porque, según observamos, él mismo ha atacado las bases que las sostienen y no tiene ya más valor —arrebatada ya su capacidad de consolidar al sujeto Ricardo- que el de reforzar su nuevo vínculo con la sociedad.

Todo lo dicho anteriormente muestra el fallo de la afiliación en Ludo y Santiago. Con esto se abre entonces un abismo entre estos personajes y Ricardo, porque mientras aquellos no encuentran las condiciones de la afiliación y no la convierten en un hecho, lo que inevitablemente los obliga a caer en un vacío; Ricardo trabaja para incorporarse a un nuevo grupo, forjar su propia ideología y contrarrestar los sistemas de dominación que la pequeña burguesía trata de extender sobre él.

Como ya sabemos, entre sus opciones se encuentran la militancia política: por un lapso de cuatro años participa en una célula donde realiza lecturas revolucionarias, escucha y hace comentarios sobre el funcionamiento de la sociedad, así como también interviene en huelgas, pintas de lemas en contra del gobierno y otros medios de protesta. Ya vimos que Santiago también entra en contacto con un grupo izquierdista en San Marcos, la Fracción Universitaria; pero finalmente lo abandona, marcando el inicio de la incertidumbre, del fracaso de la afiliación.

Ludo, por otro lado, forma parte también de una colectividad, pero en común tienen el arte y no la política ${ }^{6}$; esto no evita en él ciertos atisbos de una conciencia social, por ejemplo, cuando analiza lo que sucede en la Católica: «Ludo se daba cuenta [de] que esa universidad era algo así como la prolongación del colegio Mariano, sin curas esta vez, sin Santa Infancia, pero con maestros más ladinos y formas más sutiles de corrupción» (Ribeyro, 1973, p. 120).

Sin duda, entre los tres personajes, quien tiene el destino más crítico es Ludo, que termina convertido en un delincuente; su sensación de derrota contrasta con el sostén que le brinda el discurso socialista a Ricardo. Su conversión en asesino - hecho que curiosamente exige de él un grado alto de valor - no dialoga con la intención de Santiago de alejarse de los antivalores de la burguesía. Mientras que Ludo ve en la muerte de su padre una profecía de su propia destrucción, Santiago repudia la figura paternal cubierta por un corrompido velo, odio que solo se eclipsará junto a la muerte de don Fermín; por su parte, Ricardo se declara en contra del autoritarismo de su padre, haciendo menguar su presencia frente a la de Maese Diego, con quien llena el vacío paternal.

6 En oposición a su postura, está el personaje Segismundo, amigo de Ludo, quien sí se configura como un militante político. Graciela Coulson (1977) afirma, incluso, que, por su sola existencia, Ludo se convierte en un antihéroe. 
Existe una total coincidencia entre Ludo, Santiago y Ricardo: están enfrentados al problema de la identidad en un medio urbano que propicia su fracaso en esa búsqueda. Por supuesto, dicho medio enmarca otros problemas de tipo étnico, de clase, de creencias, etc. Ese dilema es el que nos indica que la identidad está en continua formación, nunca está dada ni fija y siempre es proclive a variar; de este modo, para los tres, por igual, existía la posibilidad de pasar con éxito de la filiación a la afiliación.

Tanto Ludo como Santiago alcanzan cierto mimetismo con la clase a la que pretendían movilizarse: «Ya no eras como ellos, Zavalita, ya eras un cholo» (Vargas Llosa, 2005, p. 584). «Todos, incluso su tía Rosalva, pasaron delante de él sin concederle otra cosa que una mirada objetiva, como si les pareciera natural que un joven pálido controlara ese ruidoso ingreso vestido con un terno anticuado» (Ribeyro, 1973, p. 79). Sin embargo, esto no hace más que comprobar que ambos protagonistas han sido inevitablemente despojados de su clase de origen; pero no hallaron, como Ricardo, otra opción que llene el vacío dejado por la anterior. Ricardo encuentra en el billar o en la militancia dos grandes opciones que motivarán su desplazamiento y suprimirán en él la amenaza del vacío. 


\section{REFERENCIAS BIBLIOGRÁFICAS}

Cotler, J. (1978). Clases, Estado y Nación en el Perú. Lima: Instituto de Estudios Peruanos.

Coulson, G. (1977). Los geniecillos dominicales o el parricidio necesario. Texto crítico, 7, pp. 154-163.

Elmore, P. (1993). Los muros invisibles: Lima y la modernidad en la novela del siglo XX. Lima: Mosca Azul Editores y El Caballo Rojo.

Marx, K. y Engels, F. (1999). Manifiesto del partido comunista. Quito: Libresa. ciones Pueblos Unidos.

(1971). La ideología alemana. 3. a ed. Montevideo: Edi-

Reyes Tarazona, R. (2005). Los verdes años del billar. 2. a ed. Lima: San Marcos.

Ribeyro, J. R. (1973). Los geniecillos dominicales. Lima: Milla Batres.

Said, E. (2004). El mundo, el texto y el crítico. Buenos Aires: Debate.

Vargas Llosa, M. (2005). Conversación en La Catedral. Barcelona: Alfaguara.

Recibido: noviembre de 2015 Aceptado: enero de 2016 